\author{
Jinsong $\mathrm{Bao}^{\mathrm{a}, \mathrm{b}}$ \\ Zihua $\mathbf{A o}^{\mathrm{b}}$ \\ Jay-lin Jane ${ }^{b}$ \\ ${ }^{a}$ Institute of Nuclear Agricultural \\ Sciences, College of Agriculture \\ and Biotechnology, \\ Zhejiang University, \\ Hua Jiachi Campus, \\ Hangzhou, P. R. China \\ ${ }^{b}$ Department of Food Science \\ and Human Nutrition, \\ lowa State University, \\ 2312 Food Sciences Building, \\ Ames, IA, USA
}

\section{Characterization of Physical Properties of Flour and Starch Obtained from Gamma-Irradiated White Rice}

\begin{abstract}
Physical and structural characteristics of rice flour and starch obtained from gammairradiated white rice were determined. Pasting viscosities of the rice flour and starch, analyzed by using a Rapid Visco Analyser, decreased continuously with the increase in irradiation dosage. Differential scanning calorimetry showed that gelatinization onset, peak and conclusion temperatures of rice flour and starch changed slightly but the enthalpy change decreased significantly with increase of irradiation dosage. All irradiated starch displayed an A-type X-ray diffraction pattern like the native starch. Gel permeation chromatography showed that the blue value ratio of the first peak (amylopectin) to the second one (amylose) decreased with the increase of the irradiation dosage. The weight-average molecular weight $\left(M_{w}\right)$ and gyration radius $\left(R_{z}\right)$ of amylopectin analyzed by using HPSEC-MALLS-RI (high-performance size-exclusion chromatography equipped with multiangle laser-light scattering and refractive index detector) decreased gradually from $1.48 \times 10^{9}\left(M_{w}\right)$ and $384.1 \mathrm{~nm}\left(R_{z}\right)$ of native rice starch to $2.36 \times 10^{8}\left(M_{w}\right)$ and $236.8 \mathrm{~nm}$ of $9 \mathrm{kGy}$-irradiated starch. The branch chainlength distribution of amylopectins determined by HPAEC-ENZ-PAD (high-performance anion-exchange chromatography with amyloglucosidase post-column on-line reactor and pulsed amperometric detector) showed that gamma irradiation had no significant effect on the amylopectin branch chains with $13 \leq \mathrm{DP} \leq 24$ and $37 \leq \mathrm{DP}$, but produced more branch chains with $6 \leq \mathrm{DP} \leq 12$ when the irradiation dosage was less than 9 kGy. It might be deduced that gamma irradiation caused the breakage of the amylopectin chains at the amorphous regions, but had little effects on the crystalline regions of starch granules, especially at low dosage irradiation.
\end{abstract}

Keywords: Rice starch; Amylopectin; Gamma irradiation; Physical properties; Structural properties

\section{Introduction}

Gamma irradiation has long been used to protect foods from insect infestation and microbial contamination during storage. As a major ingredient, starch confers structure, texture, consistency and appeal to many food systems. The effects of gamma irradiation on chemical composition of food products have received wide attention because of the concern about food safety. Gamma irradiation was considered as one of the physical modification methods of starch [1, 2]. In comparison with other physical modification methods, such as microwave [3], UV $[4,5]$, ultrahigh hydrostatic pressure [6] and hydrothermal treatment [7], gamma irradiation treatment is

Correspondence: Jinsong Bao, Institute of Nuclear Agricultural Sciences, College of Agriculture and Biotechnology, Zhejiang University, Hua Jiachi Campus, Hangzhou, 310029, P. R. China. Phone: +86 5718697 1405, Fax: +86 5718697 1202, e-mail: jsbao@zju.edu.cn.

(c) 2005 WILEY-VCH Verlag GmbH \& Co. KGaA, Weinheim rapid, convenient, and more extensive because ionizing energy penetrates through the starch granule rapidly and may cause greater damage to the starch structure. Gamma irradiation of food materials is more sanitary because the target material can be remained intact in a package or a container where the gamma rays can penetrate.

How gamma irradiation effects starch properties and food quality has been of great interests to food processors. Hence, work has been documented on irradiation of starches of rice [2, 8-10], wheat [11-13], maize [14], potato [15], and beans [16, 17]. Tomasik and Zaranyika [1] and Sohkey et al. [18] have reviewed the molecular changes in starches resulting from gamma irradiation. The starch granule structure remains visually undamaged at a low dosage of irradiation but suffers severe damage at a higher dosage (100 kGy) [2]. Crystallinity of irradiated starch increases with increasing radiation dosages in wheat and rice starches [10, 13], 
and decreased in potato starch [15]. Increase in irradiation dosage decreases viscosity and increases water solubility and acidity of starches [8, 13, 18-22]. The gelatinization enthalpy was reported to increase $[16,17]$ or decrease $[2,11,15]$ gradually with increasing irradiation dosage. Bachman et al. [22] reported that a dosage of $2 \mathrm{kGy}$ irradiation resulted in decreased and increased retrogradation of Lasco triticale and Grana wheat starches, respectively. The chain length of amylose and amylopectin displayed a progressive reduction as the irradiation dosage increased [14, 16, 21].

Although some studies have been carried out on irradiation of rice starches, few reports have been on the effects of gamma irradiation on amylopectin structure, molecular weight, and gyration radius of rice starch. In this study, we investigated how gamma irradiation affects the structures and physical properties of rice flour and starch in order to understand the mechanisms of gamma irradiation affecting starch granule structures.

\section{Materials and Methods}

\subsection{Materials}

The white japonica rice sample was bought from a local market. The moisture content of the white rice was $11.7 \%$. The white rice was divided into seven parts, each part $(100 \mathrm{~g})$ was treated with $0,0.5,1.0,3.0,5.0$, 7.0, and $9.0 \mathrm{kGy} \gamma$-radiation at room temperature, respectively. The treatment was performed in a ${ }^{60} \mathrm{Co}$ irradiator located at Zhejiang University with a dosage rate of $0.5 \mathrm{kGy} / \mathrm{h}$. After treatment, $30 \mathrm{~g}$ of white rice were ground to pass through a 100-mesh sieve on a Cyclone Sample Mill (UDY Corporation, Fort Collins, Colorado, USA), and another $50 \mathrm{~g}$ of white rice were used for starch isolation.

\subsection{Starch isolation}

White rice $(50 \mathrm{~g})$ was dispersed in $200 \mathrm{~mL} 0.05 \%$ aqueous $\mathrm{NaOH}$ at room temperature for $24 \mathrm{~h}$. After draining off the supernatant and washing with distilled water several times, the grains were wet milled and filtered through a nylon screen $(53 \mu \mathrm{m})$. The slurry was centrifuged and the top yellow layer was removed. The solids obtained by centrifugation were sequentially purified five times by the toluene-salt solution shaking procedure [23]. The clean white layer of isolated starch was washed with water and ethanol before drying in a convection oven at $32^{\circ} \mathrm{C}$ for $48 \mathrm{~h}$.

\subsection{Pasting properties}

Rice flour and starch pasting properties were determined by using a Rapid Visco Analyser (RVA, model 4, Newport Scientific, Sydney, Australia). Each rice sample (flour or starch, $3 \mathrm{~g}, 12 \%$ moisture basis) was mixed with $25 \mathrm{~g}$ of deionized water in an RVA sample canister. The idle temperature was set at $50^{\circ} \mathrm{C}$, and the following 12.5-min test profile was run: (1) $50^{\circ} \mathrm{C}$ held for $1.0 \mathrm{~min}$, (2) the temperature was linearly ramped up to $95^{\circ} \mathrm{C}$ at $4.8 \mathrm{~min}$, (3) the temperature was held at $95^{\circ} \mathrm{C}$ until $7.3 \mathrm{~min}$, (4) the temperature was linearly ramped down to $50^{\circ} \mathrm{C}$ at $11.1 \mathrm{~min}$ and (5) held at $50^{\circ} \mathrm{C}$ until $12.5 \mathrm{~min}$.

\subsection{Thermal properties}

Thermal properties of the flour and starch samples were determined by using a differential scanning calorimeter (DSC-7, Perkin-Elmer, Norwalk, CT) equipped with an intracooling II system. Approximately $3 \mathrm{mg}$ (dry basis) of samples was precisely weighed in an aluminum pan, mixed with $9 \mathrm{mg}$ of deionized water and sealed. The sample was allowed to equilibrate for $1 \mathrm{~h}$ and scanned at a rate of $10^{\circ} \mathrm{C} / \mathrm{min}$ over a temperature range of $30-110^{\circ} \mathrm{C}$. An empty pan was used as reference. Gelatinization onset $\left(T_{\mathrm{o}}\right)$, peak $\left(T_{\mathrm{p}}\right)$, conclusion $\left(T_{\mathrm{c}}\right)$ and enthalpy change $(\Delta H)$ were determined.

\subsection{X-ray diffraction pattern of starch}

X-ray diffraction patterns of the flour and starch were obtained with copper $\mathrm{K}_{\alpha}$ radiation in a diffractometer (D500 , Siemens, Madison, WI). The analysis was conducted by following the procedure of Yoo and Jane [24].

\subsection{Gel-permeation chromatography of starch}

Starch molecular-weight distribution profiles were determined by using a gel-permeation chromatographic (GPC) column $(2.6 \mathrm{~cm}$ i.d. $\times 90 \mathrm{~cm})$ packed with Sepharose CL2B gel (Pharmacia Inc., Piscataway, NJ) [25]. Starch was dispersed following the method reported by Song and Jane [26]. A starch dispersion (5 mL) containing $15 \mathrm{mg}$ starch and glucose $(0.75 \mathrm{mg}$, as a marker) was injected into the column. The column was run in the ascending mode. A solution made of distilled water containing $25 \mathrm{mM} \mathrm{NaCl}$ and $1 \mathrm{mM} \mathrm{NaOH}$ was used as eluent at a flow rate of $30 \mathrm{~mL} / \mathrm{h}$. Fractions of $4.8 \mathrm{~mL}$ per cup were collected and analyzed for total carbohydrate [27] and blue value [28] at 490 and $630 \mathrm{~nm}$, respectively. The amylopectin fractions (fraction no. 20 to 35) were collected for analyzing branch chain-length distribution. 


\subsection{Molecular weight determination of amylopectin and amylose}

The absolute molecular weights of amylopectin and amylose were determined by using high-performance size-exclusion chromatography equipped with a multiangle laser-light scattering detector (model Dawn-F, Wyatt Technology, Santa Barbara, CA) with He-Ne laser light at $632 \mathrm{~nm}$ and a refractive index detector (RI, HP1047A, Hewlett Packard) (HPSEC-MALLS-RI) [29]. A starch dispersion $(0.4 \mathrm{mg} / \mathrm{mL})$ was prepared by the same procedure used for GPC and filtered through a nylon filter $(5 \mu \mathrm{m})$ before injection. The weight-average molecular weight $\left(M_{w}\right)$ and the gyration radius $\left(R_{z}\right)$ were calculated by using ASTRA 4.7 software (Wyatt Technology, Santa Barbara, CA). Molecular weights of amylose and degraded amylopectin from gamma-irradiated starch were calculated by using a calibration curve constructed from a series of pullulan molecular weight standards $(0.58,1.22$, 2.37, 4.80, 10.0 and $18.6 \times 10^{4}$ ) (Showa Denko K. K., Tokyo, Japan).

\subsection{Amylopectin branch chain-length analysis}

The collected amylopectin fractions from the GPC analysis were combined and used for analyzing branch chainlength distribution. Amylopectin was debranched by isoamylase following the method of Jane and Chen [25]. The branch chain-length distribution of amylopectin was determined by using a high-performance anion-exchange chromatography system (Dionex-300, Sunnyvale, CA) equipped with an amyloglucosidase post-column on-line reactor and a pulsed amperometric detector (HPAECENZ-PAD) [30].

\subsection{Statistical analysis}

All measurements were made in duplicates. Analysis of variance (ANOVA) was performed with the SAS program version 8.0 (SAS Institute Inc., Cary, NC). Least significant differences for comparison of means were computed at $p<0.05$.

\section{Results and Discussion}

\subsection{Pasting viscosity}

The pasting viscosity of the gamma-irradiated rice flour decreased continuously with the increase in irradiation dosage, especially the peak viscosities and final viscosities (Fig. 1A). Effects of gamma irradiation on pasting viscosity of rice starch (Fig. 1B) were similar to that of the flour. The result was in agreement with the previous reports of the effects of irradiation on pasting viscosities of various starches [2, 8, 13, 18-22]. The reduction in viscosity indicated that gamma irradiation caused molecular degradation to starch granules. It was found that the RVA pasting viscosity profiles of starch samples (Fig. 1B) were similar to those of their flour counterparts (Fig. 1A), except that the breakdown viscosities (the difference between peak viscosity and hot paste viscosity) of starch samples were smaller than that of their flour counterparts. These differences could be attributed to the absence of proteins in rice starch [31].

\subsection{Thermal properties}

Thermal analysis of the gamma-irradiated rice flour showed that the gamma irradiation caused an increase in the onset temperature $\left(T_{0}\right)$ and decrease in conclusion temperature $\left(T_{\mathrm{c}}\right)$ and enthalpy change of gelatinization $(\Delta H)$ of rice flour, while the peak temperature $\left(T_{p}\right)$ remained unchanged (Tab. 1). For irradiated rice starch, $T_{0}$ remained unchanged, whereas $T_{\mathrm{p}}, T_{\mathrm{c}}$ and $\Delta H$ displayed a slight decrease (Tab. 1). Our previous results also showed that gamma irradiation decreased the $T_{\mathrm{p}}\left(2^{\circ} \mathrm{C}\right.$ decrease $)$ and $\Delta H$ of rice flour, after being irradiated at $50 \mathrm{kGy}$ [2]. Increases in $T_{\mathrm{o}}$ and $T_{\mathrm{p}}$ after irradiation were reported in wheat and potato starches [11, 15] and bean flour [17]. However, the $T_{\mathrm{p}}$ of wheat starch decreased after being irradiated with 446 kGy [11]. Rombo et al. [17] also reported that the $T_{\mathrm{o}}$ decreased in maize flour after gamma irradiation. The $\Delta H$ was reported to decrease in potato and wheat starches [11, 15] and bean flour [17], but to increase in maize flours [17] after irradiation. As DSC thermal properties reflect gelatinization of the crystalline part of starch, our results indicated a small decrease in the crystalline ordering in rice starches after irradiation. It was also found that the $T_{\mathrm{o}}, T_{\mathrm{p}}$ and $T_{\mathrm{c}}$ of rice starch were lower than that of the flour, whereas the enthalpy change of rice starch were higher than that of the flour counterparts (Tab. 1).

\subsection{Crystalline structure}

The X-ray diffraction patterns of the irradiated rice flour and starch showed that they all displayed the A-type Xray diffraction patterns. The native rice starch and flour had a crystallinity of $36.1 \%$ and $31.5 \%$, respectively (Fig. 2). Starch irradiated at $0.5 \mathrm{kGy}$ had a crystallinity of $35.6 \%$, whereas all other starches irradiated at larger dosage had greater crystallinities than the normal starch (Fig. 2). The $1 \mathrm{kGy}$ treatment gave the highest crystallinity (40\%), further increase in irradiation dosage decreased the crystallinity. On the other hand, all irradiated flours 

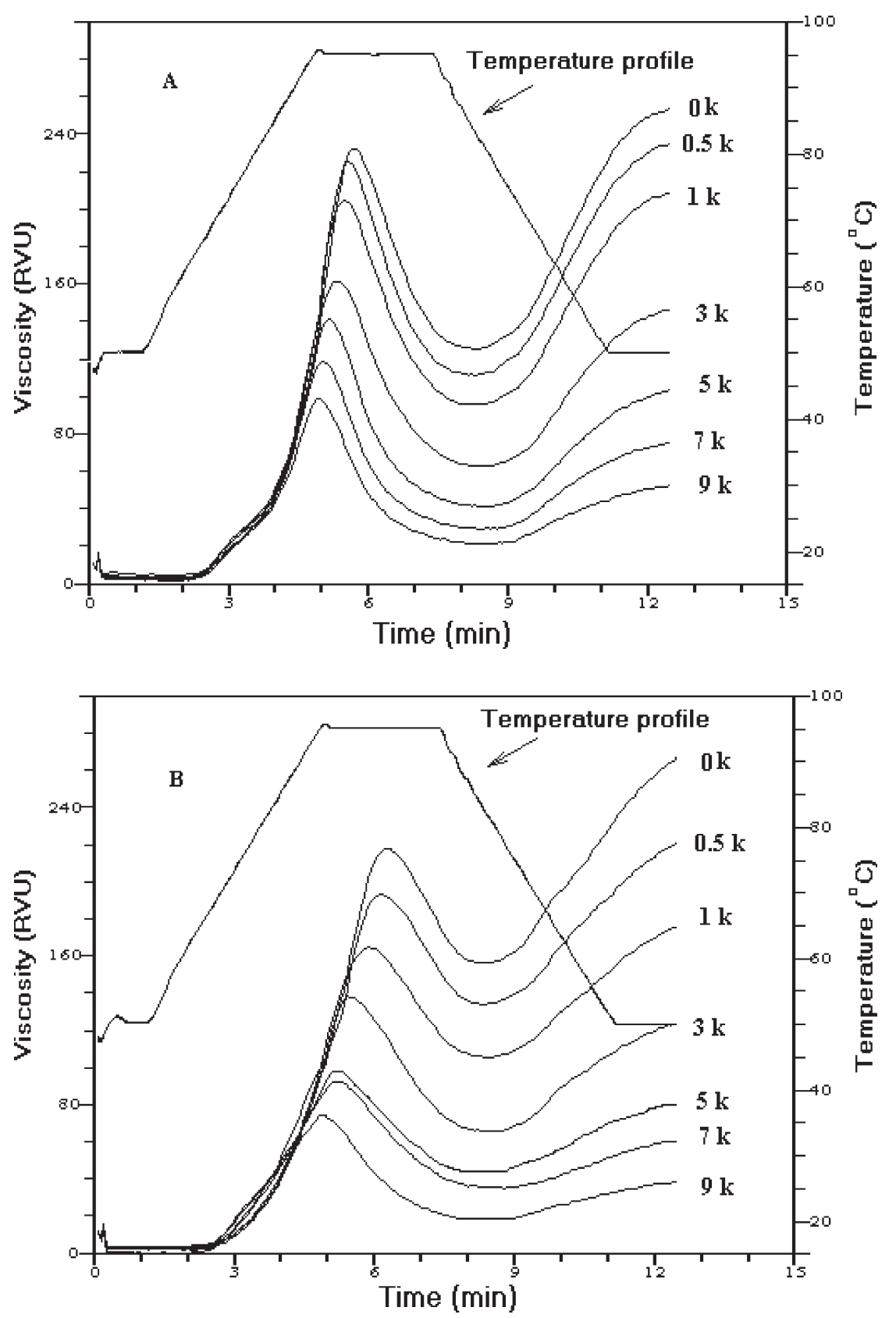

Fig. 1. Rapid Visco Analyser pasting profiles of rice flour $(A)$ starches $(B)$ obtained from gamma-irradiated white rice. had a decreased crystallinity as compared with that of the native flour (Fig. 2). Increased crystallinity of starches, determined by X-ray diffraction techniques, has been reported in wheat [13] and rice [10] starches. The decrease in $\Delta H$ of irradiated potato starch was reported to be in agreement with the decrease in crystallinity [15]. In the present study, the decrease in $\Delta H$ of irradiated rice flour and starch were not in agreement with the decrease in crystallinity (Tab. 1, Fig. 2), indicating the crystallinity of irradiated starch samples was not always correlated with their $\Delta H$.

\subsection{Molecular weight distribution}

The molecular weight distribution of rice starch was determined by using gel permeation chromatography. The results showed that rice starch displayed two peaks, representing amylopectin (first peak, fractions 20 to 35) and amylose (second peak, fractions 56 to 82) (Fig. 3). The percent of total carbohydrate content and the blue value of peak 1 (amylopectin part) decreased while that of the peak 2 increased. The total carbohydrate contents of fractions 36 to 56 increased for samples with higher irra- 
Tab. 1. Thermal properties of rice flour and starch obtained from gamma-irradiated white rice.

\begin{tabular}{|c|c|c|c|c|c|c|c|c|}
\hline \multirow{2}{*}{$\begin{array}{l}\text { Irradiation } \\
\text { dosage [kGy] }\end{array}$} & \multicolumn{4}{|c|}{ Flour } & \multicolumn{4}{|c|}{ Starch } \\
\hline & $T_{\circ}\left[{ }^{\circ} \mathrm{C}\right]$ & $T_{\mathrm{p}}\left[{ }^{\circ} \mathrm{C}\right]$ & $T_{\mathrm{c}}\left[{ }^{\circ} \mathrm{C}\right]$ & $\Delta H[\mathrm{~J} / \mathrm{g}]$ & $T_{\mathrm{o}}\left[{ }^{\circ} \mathrm{C}\right]$ & $T_{\mathrm{p}}\left[{ }^{\circ} \mathrm{C}\right]$ & $T_{\mathrm{c}}\left[{ }^{\circ} \mathrm{C}\right]$ & $\Delta H[\mathrm{~J} / \mathrm{g}]$ \\
\hline 0 & $57.7 \mathrm{c}$ & $64.9 \mathrm{a}$ & $71.6 \mathrm{a}$ & $7.5 \mathrm{a}$ & $56.4 \mathrm{a}$ & $63.6 \mathrm{a}$ & $69.6 \mathrm{a}$ & $12.1 \mathrm{a}$ \\
\hline 0.5 & $57.0 \mathrm{c}$ & $64.5 \mathrm{a}$ & $71.3 \mathrm{ab}$ & $7.6 \mathrm{a}$ & $56.3 \mathrm{a}$ & $62.8 \mathrm{bc}$ & $69.2 a b$ & $11.5 a b$ \\
\hline 1 & $58.1 \mathrm{bc}$ & $64.8 \mathrm{a}$ & $71.2 \mathrm{abc}$ & $7.1 \mathrm{ab}$ & $56.3 \mathrm{a}$ & $62.5 \mathrm{c}$ & $69.2 \mathrm{ab}$ & $10.5 \mathrm{ab}$ \\
\hline 3 & $57.5 \mathrm{c}$ & $64.4 \mathrm{a}$ & $70.7 \mathrm{bcd}$ & $7.0 \mathrm{ab}$ & $56.4 \mathrm{a}$ & $62.4 \mathrm{c}$ & 68.7 b & $9.7 \mathrm{~b}$ \\
\hline 5 & $58.2 \mathrm{bc}$ & $64.7 \mathrm{a}$ & $70.9 \mathrm{abc}$ & $5.5 \mathrm{bc}$ & $56.7 \mathrm{a}$ & $63.1 \mathrm{~b}$ & $69.2 \mathrm{ab}$ & $10.3 \mathrm{ab}$ \\
\hline 7 & 59.9 a & $64.3 \mathrm{a}$ & $70.0 \mathrm{~d}$ & $3.9 \mathrm{~cd}$ & $56.7 \mathrm{a}$ & $62.8 \mathrm{bc}$ & $69.3 a b$ & $10.3 a b$ \\
\hline 9 & $59.0 \mathrm{ab}$ & $64.5 \mathrm{a}$ & $70.4 \mathrm{~cd}$ & $3.8 \mathrm{~d}$ & $56.4 \mathrm{a}$ & $62.7 \mathrm{bc}$ & $69.0 \mathrm{ab}$ & $10.8 \mathrm{ab}$ \\
\hline
\end{tabular}

Different letters in each column indicate significant difference at the 0.05 level.

$T_{\mathrm{o}}$ : onset temperature, $T_{\mathrm{p}}$ : peak temperature, $T_{\mathrm{c}}$ : conclusion temperature, and $\Delta H$ : enthalpy of gelatinization.

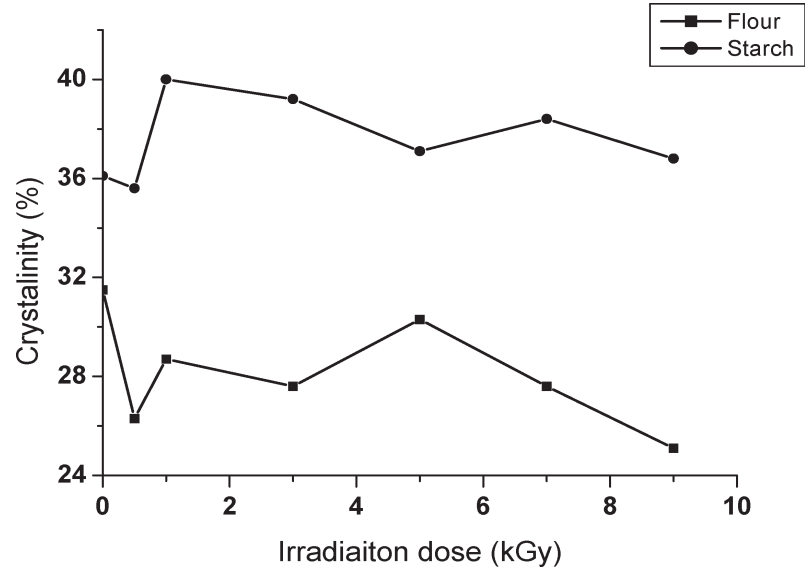

Fig. 2. Crystallinity of rice flours and starch obtained from gamma-irradiated white rice.

diation dosage treatments such as $5 \mathrm{kGy}, 7 \mathrm{kGy}$ and 9 kGy. Similarly, the blue value ratio of the first peak (amylopectin) to the second peak (amylose) decreased with the increase of the irradiation dosage. The results indicated that the amylopectin molecules were degraded by increasing dosage irradiation. These results agreed with that reported previously $[14,17]$.

\subsection{Amylopectin and amylose molecular weight and size}

The molecular weights of amylopectin and amylose were determined by using high-performance size-exclusion chromatography equipped with multiangle laser-light scattering and refractive index detectors. The weightaverage molecular weight $\left(M_{w}\right)$ of untreated rice amylopectin and amylose was $1.48 \times 10^{9}$ and $3.85 \times 10^{5}$, respectively, which were similar to that previously reported [29]. The $M_{w}$ of amylopectin and amylose decreased with the increase in irradiation dosage, and the $M_{w}$ of amylopectin and amylose decreased to $2.36 \times 10^{8}$ and $3.66 \times 10^{5}$ at $9 \mathrm{kGy}$, respectively (Tab. 2). The $Z$-average radius of gyration $\left(R_{z}\right)$ of amylopectin was decreased gradually from $289.0 \mathrm{~nm}\left(R_{z}\right)$ of the untreated starch to $204.2 \mathrm{~nm}\left(R_{z}\right)$ of $9 \mathrm{kGy}$ irradiated rice starch (Tab. 2), indicating the decrease in the molecular size of amylopectin due to irradiation. Sokhey and Chinnaswamy [14] reported that the molecular weight of fraction I decreased with increasing irradiation dosage, they found that the molecular weights of fractions II and III were increased at lower irradiation dosage and then decreased at higher dosage.

Tab. 2. Weight average molecular weight $\left(M_{w}\right)$ of amylopectin and peak two (amylose and degraded amylopectin) and gyration radii of amylopectin $\left(R_{z}\right)$ of the rice starch obtained from gamma-irradiated white rice.

\begin{tabular}{llll}
\hline $\begin{array}{l}\text { Irradiation } \\
\text { dosage }[\mathrm{kGy}]\end{array}$ & $\begin{array}{l}\text { Amylopectin } \\
M_{w}\left(M_{w} \times 10^{8}\right)\end{array}$ & $R_{z}[\mathrm{~nm}]$ & $\begin{array}{l}\text { Peak two } \\
M_{w}\left(M_{w} \times 10^{5}\right)\end{array}$ \\
\hline 0 & $14.77 \mathrm{a}$ & $384.1 \mathrm{a}$ & $3.85 \mathrm{a}$ \\
0.5 & $10.75 \mathrm{~b}$ & $361.2 \mathrm{a}$ & $3.81 \mathrm{ab}$ \\
1 & $9.80 \mathrm{~b}$ & $345.2 \mathrm{a}$ & $3.81 \mathrm{ab}$ \\
3 & $4.67 \mathrm{c}$ & $262.4 \mathrm{~b}$ & $3.80 \mathrm{~b}$ \\
5 & $2.78 \mathrm{~d}$ & $254.5 \mathrm{~b}$ & $3.74 \mathrm{c}$ \\
7 & $2.38 \mathrm{~d}$ & $234.7 \mathrm{~b}$ & $3.73 \mathrm{c}$ \\
9 & $2.36 \mathrm{~d}$ & $236.8 \mathrm{~b}$ & $3.66 \mathrm{~d}$ \\
\hline
\end{tabular}

Different letters in each column indicate significant difference at the 0.05 level.

\subsection{Amylopectin branch chain-length distribution}

The amylopectin collected from GPC was used for analyzing branch chain-length distribution. It seemed that the gamma irradiation had no significant effect on the amylo- 


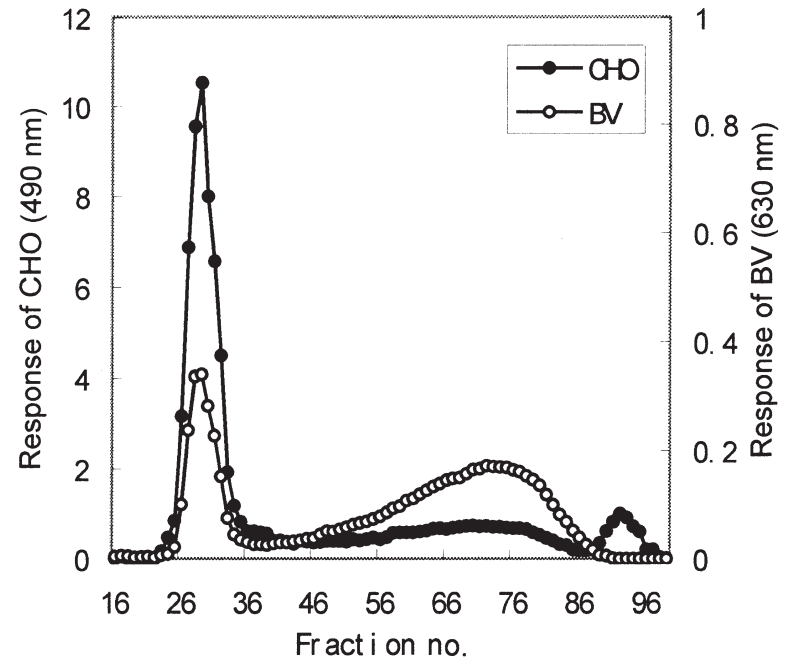

Reference

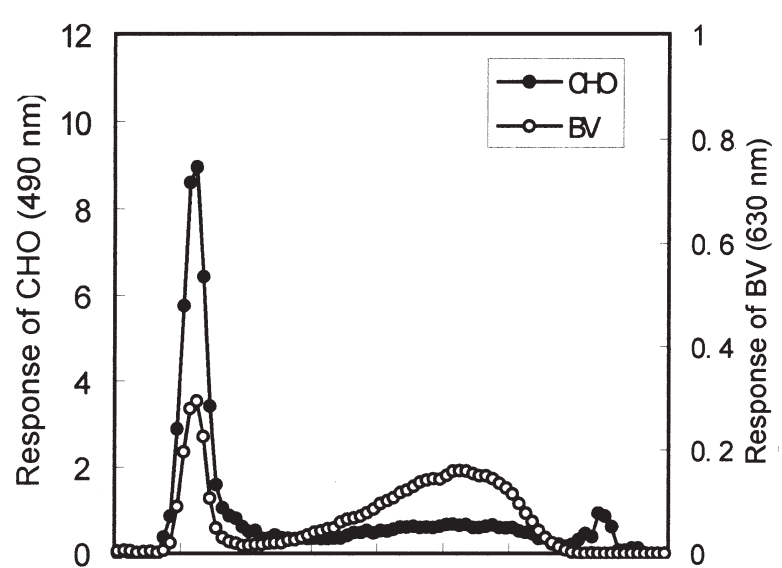

$\begin{array}{lllllllll}16 & 26 & 36 & 46 & 56 & 66 & 76 & 86 & 96\end{array}$

Fract $i$ on no.

$1 \mathrm{kGy}$

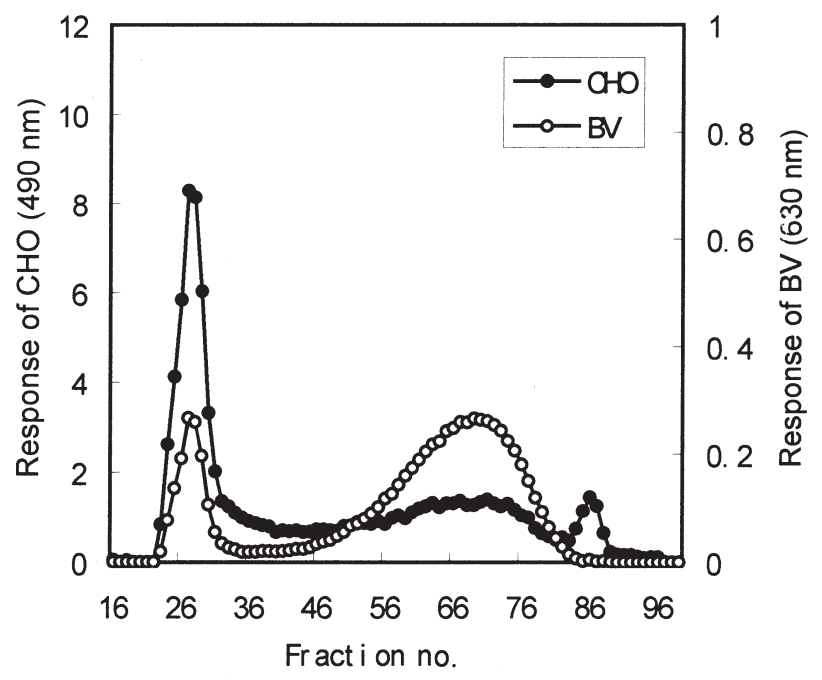

$$
5 \text { kGy }
$$

(c) 2005 WILEY-VCH Verlag GmbH \& Co. KGaA, Weinheim
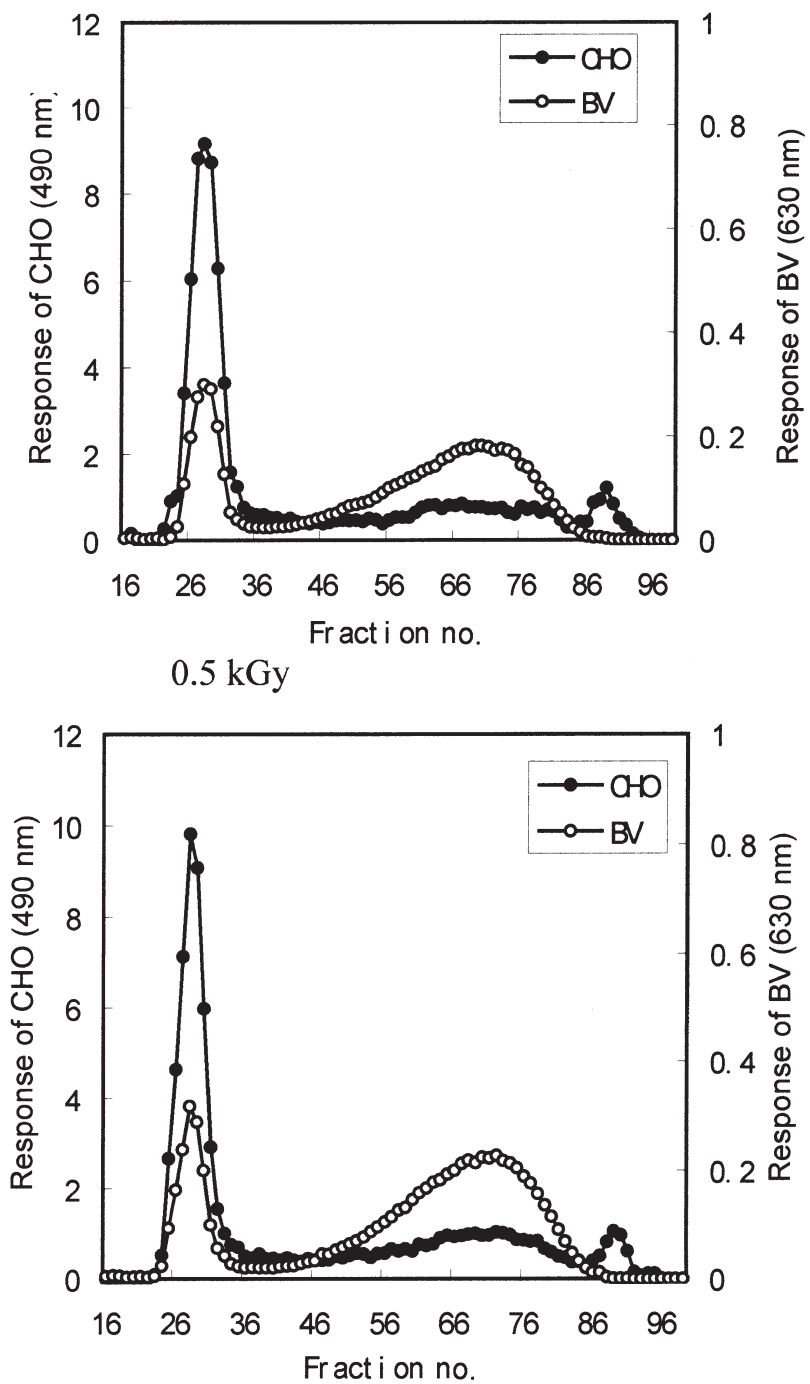

$3 \mathrm{kGy}$

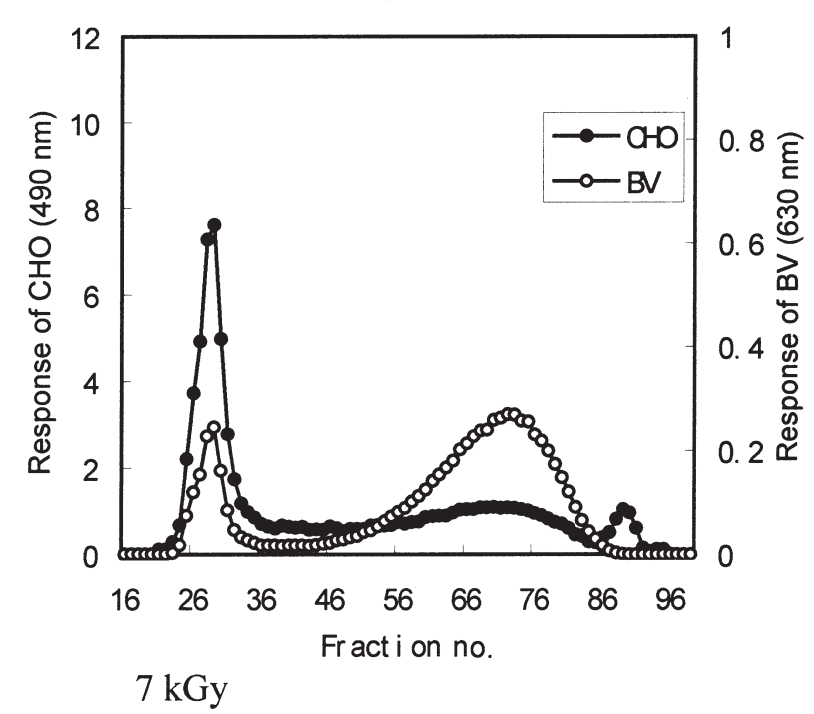

www.starch-journal.de 


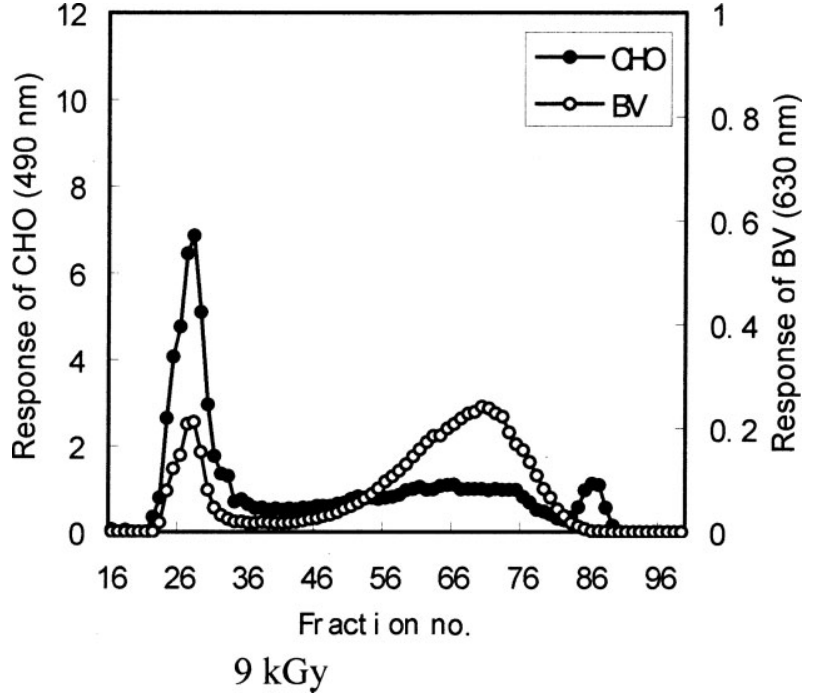

Fig. 3. Sepharose CL-2B gel permeation chromatography profiles of rice starches obtained from gamma-irradiated white rice, $\mathrm{CHO}$ : total carbohydrate content, BV: blue value.

pectin branch chains with $13 \leq \mathrm{DP} \leq 24$ and $37 \geq \mathrm{DP}$ (Tab. 3). More branch chains with $6 \leq \mathrm{DP} \leq 12$ were produced when the irradiation dosage was less than $9 \mathrm{kGy}$. Branch chains with $25 \leq \mathrm{DP} \leq 36$ decreased when the irradiation dosage was less than $9 \mathrm{kGy}$. However, less chains with $6 \leq \mathrm{DP} \leq 12$ but more chains with $25 \leq \mathrm{DP} \leq 36$ were produced under 9 kGy treatment (Tab. 3).

The results indicated that gamma irradiation fragmented amylopectin and decreased the molecular weight. The fragmentation mostly resulted from the cleavage at the amorphous regions, instead of at crystallite regions, because there was significant decrease in the gyration radius of the amylopectin molecule (Tab. 2) but little change in the amylopectin branch chain length (Tab. 3). This mechanism was similar to that of the acid hydrolysis of starch [32]. Another mechanism was that gamma irradiation might cause both cleavage and cross-linking of starch chains. The increase in the branch chains $>$ DP 25 and decrease in the branch chain $\leq$ DP 24 at 9 kGy indicated that cross-linking might occur between branch chains. Gamma irradiation produced free radicals on the starch molecules [4], which might induce cross-linking, but this mechanism awaits further study. On the other hand, gamma irradiation could also damage amylose molecules, causing a decrease in their molecular weights (Tab. 2). However, the possibility to attack amylose was considered lower than to attack amylopectin because the amylose content in normal rice starch is smaller than that of amylopectin.

\section{Conclusion}

Gamma irradiation caused significant reduction in the RVA viscosity of rice flour and starch, in the $\Delta H$ of irradiated rice flour, and in the molecular weight and gyration radius of amylopectin, but caused little changes of $T_{0}, T_{p}$ and $T_{\mathrm{c}}$ of both rice flour and starch. The crystallinity increased in irradiated starch but decreased in the irradiated flour as compared with the native samples. It can be concluded from the present study that gamma irradiation causes cleavage of amylopectin molecules at the amorphous regions.

Tab. 3. The amylopectin branch chain-length of rice starches obtained from gamma-irradiated white rice.

\begin{tabular}{lllll}
\hline $\begin{array}{l}\text { Irradiation } \\
\text { dosage [kGy] }\end{array}$ & \multicolumn{3}{l}{ Distribution [\%] } & \\
\cline { 2 - 5 } & DP 6-12 & DP 13-24 & DP 25-36 & DP $\geq 37$ \\
\hline 0 & $25.9 \pm 0.08 \mathrm{c}$ & $50.0 \pm 0.19 \mathrm{a}$ & $10.9 \pm 0.13 \mathrm{bc}$ & $13.3 \pm 0.14 \mathrm{a}$ \\
0.5 & $25.4 \pm 0.88 \mathrm{c}$ & $49.0 \pm 1.48 \mathrm{a}$ & $11.3 \pm 0.64 \mathrm{~b}$ & $14.3 \pm 1.73 \mathrm{a}$ \\
1 & $26.0 \pm 0.10 \mathrm{a}-\mathrm{c}$ & $50.0 \pm 0.11 \mathrm{a}$ & $10.7 \pm 0.04 \mathrm{c}$ & $13.3 \pm 0.05 \mathrm{a}$ \\
3 & $26.3 \pm 0.09 \mathrm{ab}$ & $49.5 \pm 0.10 \mathrm{a}$ & $10.9 \pm 0.28 \mathrm{bc}$ & $13.3 \pm 0.29 \mathrm{a}$ \\
5 & $26.7 \pm 0.24 \mathrm{a}$ & $49.6 \pm 0.25 \mathrm{a}$ & $10.7 \pm 0.16 \mathrm{c}$ & $13.0 \pm 0.34 \mathrm{a}$ \\
7 & $26.0 \pm 0.08 \mathrm{a}-\mathrm{c}$ & $49.5 \pm 0.40 \mathrm{a}$ & $11.2 \pm 0.13 \mathrm{bc}$ & $13.3 \pm 0.61 \mathrm{a}$ \\
9 & $24.5 \pm 0.00 \mathrm{~d}$ & $49.2 \pm 0.29 \mathrm{a}$ & $11.9 \pm 0.13 \mathrm{a}$ & $14.4 \pm 0.16 \mathrm{a}$ \\
\hline
\end{tabular}

Data were expressed by mean $\pm \mathrm{SD}(n=2)$. Different letters in each column indicate significant difference at the 0.05 level. 


\section{References}

[1] P. Tomasik, M. F. Zaranyika: Nonconventional methods of modification of starch. Adv. Carbohydr. Chem. Biochem. 1995, 51, 243-320.

[2] J. S. Bao, H. Corke: Pasting properties of $\gamma$-irradiated rice starches as affected by pH. J. Agri Food Chem. 2002, 50, 336-341.

[3] G. Lewandowicz, T. Janowski, J. Fornal: Effect of microwave radiation on physico-chemical properties and structure of cereal starches. Carbohydr. Polym. 2000, 42, 193-199.

[4] A. C. Bertolini, C. Mestres, P. Colonna, J. Raffi: Free radical formation in UV- and gamma-irradiated cassava starch. Carbohydr. Polym. 2001, 44, 269-271.

[5] M. Fiedorowicz, P. Tomasik, Y. Sangguan, T. L. Seung: Molecular distribution and pasting properties of UV-irradiated corn starches. Starch/Stärke 1999, 51, 126-131.

[6] H. Katopo, Y. Song, J. L. Jane: Effect and mechanism of ultrahigh hydrostatic pressure on the structure and properties of starches. Carbohydr. Polym. 2002, 47, 233-244.

[7] H. Jacobs, J. A. Delcour: Hydrothermal modifications of granular starch, with retention of the granular structure: A review. J. Agric. Food Chem. 1998, 46, 2895-2905.

[8] J. S. Bao, Q. Y. Shu, Y. W. Xia, C. Bergman, A. McClung: Effects of gamma irradiation on aspects of milled rice (Oryza sativa) end-use quality. J. Food Qual. 2001, 24, 327-336.

[9] V. C. Sabularse, J. A. Liuzzo, R. M. Rao, R. M. Grodner: Cooking quality of brown rice as influenced by gamma-irradiation, variety and storage. J. Food Sci. 1991, 56, 96-98, 108.

[10] M. Wootton, H. Djojonegoro, R. Driscoll: The effect of gamma-irradiation on the quality of Australian rice. J. Cereal Sci. 1988, 7, 309-315.

[11] K. Cieśla, A. C. Eliasson: DSC studies of gamma irradiation influence on gelatinization and amylose-lipid complex transition occurring in wheat starch. Radiat. Phys. Chem. 2003, 68, 933-940.

[12] H. Koksel, S. Celik, T. Tuncer: Effects of gamma irradiation on durum wheat and spaghetti quality. Cereal Chem. 1996, 73, 506-509.

[13] L. A. MacArthur, B. L. D'Appolonia: Gamma radiation of wheat. II. Effects of low-dosage radiations on starch properties. Cereal Chem. 1984, 61, 321-326.

[14] A. S. Sokhey, R. Chinnaswamy: Chemical and molecular properties of irradiated starch extrudates. Cereal Chem. 1993, 70, 260-268.

[15] K. Cieśla, A. C. Eliasson: Influence of gamma radiation on potato starch gelatinization studied by differential scanning calorimetry. Radiat. Phys. Chem. 2002, 64, 137-148.

[16] P. Rayas-Duarte, J. H. Rupnow: Gamma-irradiation affects some physical properties of dry bean (Phaseolus vulgaris) starch. J. Food Sci. 1993, 58, 389-394.
[17] G. O. Rombo, J. R. N. Taylor, A. Minnaar: Irradiation of maize and bean flours: effects on starch physicochemical properties. J. Sci. Food Agric. 2004, 84, 350-356.

[18] A. S. Sokhey, M. A. Hanna, M. Wootton, D. J. Gallant: Properties of irradiated starches. Food Struct. 1993, 12, 397410.

[19] R. M. A. El-Saadany, A. El-Fatah, A. El-Safti, F. M. El-Saadany: Effect of gamma irradiation on Egyptian sweet potato starch. Stärke 1974, 26, 190-192.

[20] R. M. A. El-Saadany, F. M. El-Saadany, Y. H. Foda: Degradation of corn starch under the influence of gamma irradiation. Stärke 1976, 28, 208-214.

[21] M. Roushdi, A. Harras, A. El-Meligi, M. Bassim: Effect of high doses of gamma rays on corn grains. II. Influence on some physical and chemical properties of starch and its fractions. Starch/Stärke 1983, 35, 15-18.

[22] S. Bachman, H. Gambus, A. Nowotna: Effect of gammaradiation on some physicochemical properties of triticale starch. Pol. J. Food Nutr. Sci. 1997, 6, 31-39.

[23] A. M. L. McDonald, J. R. Stark: A critical examination of procedures for the isolation of barley starch. J. Inst. Brewing 1988, 94, 125-132.

[24] S. H. Yoo, J. Jane: Structural and physical characteristics of waxy and other wheat starches. Carbohydr. Polym. 2002, 49, 297-305.

[25] J. L. Jane, J. F. Chen: Effect of amylose molecular size and amylopectin branch chain length on paste properties of starch. Cereal Chem. 1992, 69, 60-65.

[26] Y. Song, J. Jane: Characterization of barley starches of waxy, normal, and high amylose varieties. Carbohydr. Polym. 2000, 41, 365-377.

[27] M. Dubois, K. A. Gilles, J. K. Hamilton, P. A. Rebers, F. Smith: Colorimetric method for determination of sugars and related substances. J. Anal. Chem. 1956, 28, 350-356.

[28] B. O. Juliano: A simplified assay for milled-rice amylose. Cereal Sci. Today 1971, 16, 334-340.

[29] S. H. Yoo, J. Jane: Molecular weights and gyration radii of amylopectins determined by high-performance size-exclusion chromatography equipped with multi-angle laser-light scattering and refractive index detectors. Carbohydr. Polym. 2002, 49, 307-414.

[30] K. S. Wong, J. Jane: Quantitative analysis of debranched amylopectin by HPAEC-PAD with a postcolumn enzyme reactor. J. Liq. Chromatogr. Related. Technol. 1997, 20, 297310.

[31] M. A. Fitzgerald, M. Martin, R. M. Ward, W. D. Park, H. J. Shead: Viscosity of rice flour: A rheological and biological study. J. Agric. Food Chem. 2003, 51, 2295-2299.

[32] R. Hoover: Acid-treated starches. Food Rev. Int. 2000, 16, 369-392.

(Received: April 21, 2005)

(Revised: June 28, 2005)

(Accepted: June 29, 2005) 